\title{
Social Informatics Today and Tomorrow: Status, Problems and Prospects of Development of Complex Lines in the Field of Science and Education
}

\author{
Konstantin Kolin
}

kolinkk@mail.ru, The Institute of Informatics Problems of the Russian Academy of Sciences, Moscow, Russia

\begin{abstract}
We consider the current state and current problems of development of Social Informatics in Russia as an important direction in science and education, studying information processes and systems in a modern society in terms of globalization and informatization of the complex. Russian scientists set out the approach to the study of Social Informatics in the education system in the time of substantial upgrading in terms of becoming an information society.
\end{abstract}

Keywords: Social Informatics, philosophy of information, education.

\section{Social Informatics - Scientific Basis of the Information Society}

Studies show that one of the most important social trends of civilization in the $21^{\text {st }}$ Century is the transition from an industrial to an information society, in which the main targets and the results for the majority of the employed population will be information products and services. Therefore, today there is an objective social need for a systematic study of the information society in the field of scientific knowledge and disseminating it through a modernized educational system. A legitimate reaction of science to this new social need was the establishment of a new research direction in the field of informatics that appeared in Russia in the mid-1980s and became known as Social Informatics.

The founder of this direction, in its modern sense, was a famous Russian philosopher A.D. Ursul (Ursul,1990), who proposed a conceptual approach to defining the basic goals and tasks of Social Informatics, linking them with the global problem of informatization of society, in which "socialization" was the most important achievement of Informatics. In his works, he showed that the process of the informatization of society must be socially-oriented in its very essence. This means informatics and information technology function only as tools that serve a man so that he can better master the information and use it for social progress. He is also one of the first researchers to point to the crucial importance of the humanistic orientation of the information society, which must not evolve spontaneously, as it creates not only new opportunities for the individual and society, but also new threats (Ursul, 1993).

This is what determines the relevance of complex scientific research aimed at studying the regularities of the process of informatization of society and, on this basis, of scientifically sound concepts, predictions, and recommendations for how the Information Society will inform scientific, technical, economic, educational, and cultural policy in international, national, and regional contexts.

The solution to these problems and to promoting social science as fundamental and applied science is already emerging in our world of the global information society, which some scientists see as a new, higher stage of civilization.

\section{The Object and Subject of Social Informatics and Its Main Goal}

Social Informatics is a typical example of a new interdisciplinary scientific field, formed at the junction of several natural and human sciences under the influence of integration arising from the recently emerging social need to develop the scientific base of the postindustrial society - the Infor- 
mation Society. Kolin $(1994 ; 1995)$ argues in some detail for the legality of the allocation of Social Informatics as an independent scientific discipline. The criteria are the existence of the object and purpose of the study, as well as the discipline needed to undertake research.

With respect to the subject of Social Informatics research, it represents only a certain set of properties of the object of research. Such a combination at this stage of development of Social Informatics should recognize the global process of the informatization of society and its impact on social structures, as well as the role and position of the individual in society.

In doing so, we would like to emphasize that this effect is bilateral, i.e., the social structure of society and people's attitude to the process of informatization, in turn, have a significant impact on the nature and pace of the development of this process.

Thus, the fundamental problem of Social Informatics as science is the problem of coordinating development of the society and its global informatization (Ursul, 1993). This problem is now especially important and relevant as it is most closely connected with the problem of overcoming the crisis of modern civilization and its transition to a path of sustainable and sound development based on the mastery of information and widespread use of new knowledge and technologies.

The main objectives of studying the problems of Social Informatics should be the identification and analysis of new opportunities for human development and society in the new reality of information, as well as new threats and risks to their livelihoods, which already exist or may arise in the future.

\section{The Concepts and Methods of Social Informatics}

The main difference in approaching the study of these problems from Social Informatics is that in this approach is the fundamental scientific hypothesis of Informatics. Its essence is that the world around us has the property of information, and, therefore, the unity of the regularities of the phenomenon of information in nature and society is due to a common origin. Therefore, the fundamental basis for the development of Social Informatics is that achievements in the field of philosophy and theoretical foundations of Informatics, which today is seen in Russia as the basic science, are becoming increasingly interdisciplinary and philosophical in significance.

As for a genuine scientific methodology of Social Informatics, it should be recognized that it is currently still in the stage of formation. An important distinctive feature of this method is the use of long $\neg$ aggregate different types of scientific approach to the analysis and synthesis of the issues and processes. The most important of them are informative, systematic, co-evolutionary and social approaches.

The essence of the information approach is that, when studying a process or phenomenon information aspects come first. Experience has shown that, very often, it allows us to see many seemingly familiar and well-known processes and phenomena in a completely new light, revealing the global nature of the information, which, in many cases, is the main cause of the temporal development of these processes.

The Co-evolutionary approach to Social Informatics was proposed by A.D. Ursul. It points to the need of unity and mutual indissociability of the development of society and its information. They manifest a coordinated development.

The Social approach to the problems studied by Social Informatics is that these studies focus primarily on social aspects of the process of informatization - its humanistic orientation. These include, primarily, the problem of the formation and development of the Information Society, new opportunities and challenges of democratization, freedom of information and security rights, etc.

The methodological apparatuses of Social Informatics, other than governmental approaches specified above, also include information and methods of modeling the process, as well as traditional methods of social sciences for social monitoring, forecasting, and management. It can be assumed that the composition and power of Social Informatics methodology in the coming years will grow rapidly with the expansion and deepening of its subject area, and must respond to the need to meet new challenges imposed by the development of practice in the Information Society. 


\section{The Structure of the Subject Area of Social Informatics}

The detailed structure of the substantive areas of Social Informatics as a distinct academic discipline was first developed in Russia (Kolin,1994; Kolin, 1995; Kolin, 2000; Kolin, 2003). Discussion of these results was carried out at a meeting of the Presidium of the Russian Academy of Natural Sciences, as well as a number of academic seminars and conferences on Informatics, in particular, the $2^{\text {nd }}$ UNESCO International Congress "Education and Informatics." Russia's national report to the Congress, "Social Informatics," was included as one of four main sections of the new perspective course, "Fundamentals of Informatics," which was recommended for the advanced education system.

This training course included the following four sections:

1. Information resources of society, their properties, structure, and topology. This is the study of the needs of society in information resources to achieve the objectives of social development (the problem of insufficient information).

2. Information capacity of the society that determines its ability to create and effectively use in formation resources. This should include all of the problems associated with the formation of an information infrastructure and information environment of society, i.e., the establishment and operation of the generation, storage, and dissemination of information resources, as well as the development of tools for the strengthening and effective use of information resources (the problems of availability of information).

3. The Information Society, patterns and problems of its formation and development. This includes the problem of developing the information economy, as well as changes in the structure of employment in the information society. It includes, furthermore, the problem of the democratization of society. Accessibility to the necessary information and its reliability is an essential condition for the practical realization of civil rights and liberties for all its members. Essential to solving these problems is the development of the intellectual potential of society, i.e., its ability to produce and absorb new knowledge, as well as the development of the information culture of the society, describing its ability to adapt to the development of the new information environment of human existence.

4. Humans in the Information Society. This explores new opportunities and new challenges of personal development in the Information Society, information, and processes of education rights, and the development of creative abilities through the use of creative achievements of science and information technology.

Practice has shown that this structure is problematic for social science, as an independent, interdisciplinary scientific direction was quite good; as mentioned above, the main problems that make up this region still remain very important and relevant.

\section{Social Informatics and the Scientific Outlook}

Given the systematic and comprehensive study of the new information and the reality of the global information society, using methods of Social Informatics seems very important today not only from a pragmatic point of view, but also a humanitarian aspect, because it promotes the formation of people's modern scientific outlooks. Conditions of the information society significantly altered not only the usual stereotypes of people's behavior, but also their traditional perceptions of space and time, wealth and poverty, equality and inequality, freedom and responsibility, and quality of life. Indeed, today the quality of human life is largely determined by the availability of necessary information and advanced information communications, as well as the level of consumption of information products and services.

Modern society is increasingly using such new concepts as the digital divide, information poverty, information culture identity, e-government, and many others. The rapidly evolving information 
economy, which, in some countries such as India, is becoming an important source of exports and job creation for educated people. Many countries, including Russia, are increasingly developing open education systems based on the use of digital educational resources and distance learning technologies.

Information security is becoming one of the most important conditions for ensuring national and international security, as well as the personal security of each person (Kolin, 2006). Today's global financial and economic crisis is a very good example. At the present stage of the knowledge society, we are beginning to realize the strategic importance of the development of linguistic and philological culture of the individual and society. Indeed, the language-not the only means of communication, but also a means of cognition-is needed for modeling the world in the mind of man.

\section{Social Informatics and Education}

Social Informatics has actively developed in Russia for 20 years, starting in 1989. At the present time, it is one of the most important parts of Informatics, a scientific basis for the formation of information society in Russia, as well as a means to explore new opportunities and new challenges in the human conditions of a new information environment and professional life. Many of the problems of Social Informatics have been taught at secondary and tertiary levels, as well as in scientific training and professional development of graduates. However, the system of higher education of Russia today faces a new topical issue: to prepare millions of citizens, especially the new generation, for life and professional activities in the Global Information Society.

The analysis shows that, in order to resolve this problem, the information orientation of the content of the educational system design solutions here could be a broad introduction to the system of general education discipline "Social Informatics," which has, as its purpose, to ensure the formation of human knowledge and skills needed by them in a highly automated information environment.

The experience of studying the course of Social Informatics in Russia: Russia is the world leader in the field of the scientific study of Social Informatics and the methodology of studying these problems in the education system. Suffice to say that the term "Social Informatics" was proposed in Russia more than 20 years ago. Over the years, there has been an evolution of the complex content of the term, and today it includes a specific and very large section of Informatics, which examines the basic patterns and forms of information in society, as well as the ways and problems of its social use.

As for the study of Social Informatics in higher education, this process began in Russia in the late 1980s, when we came to realize the social significance of the information society. Therefore, a number of Russian universities have established specialized departments of Social Informatics. Russia also chairs the Association of Social Informatics, which continues its work to date.

In the mid 1990s, Moscow State Social University (now the Russian State Social University) established the Institute of Informatics Problems of the Russian Academy of Sciences, the first Social Informatics in the world, which has successfully operated for five years and produced a significant number of professionals with sociologist-informatics expertise.

The experience of the educational activities of the faculty reported in the $2^{\text {nd }}$ UNESCO International Congress, "Education and Informatics," was approved by the Congress and has since been used in a number of Russian educational institutions.

Methodological Support course: The first pilot training program for the higher education system, "Social Informatics,", was created in 1997 at the Institute of Informatics Problems of the Russian Academy of Sciences with the active assistance of the UNESCO Institute for Information Technologies in Education; it takes into account the scientific and methodological recommendations of UNESCO.

In subsequent years, the program has been developed to a fully-fledged modular basic program of educational discipline, represented on the Internet and well known to professionals working in the field of education (Kolin, 2001). 
In line with the content of this basic modular program was developed a training manual, which was issued in 2000, then reissued in 2003 along with the text of the modular training course, "Social Informatics," for the higher education system (Kolin,2000; Kolin, 2003a). There are numerous references to these publications on the Internet today, which indicate a high demand for this course in the Russian education system.

Prospects for further application of social science courses in the Masters program of Russian universities: In 2008, specialists at the Russian Academy of Sciences, together with scientists and teachers of the Siberian Federal University, issued proposals to substantially increase the range of educational courses in this area for the master's system of teacher education. The " Social Informatics " academic discipline is fundamentally new in the Russian system of higher education.

The main objective of this discipline is to provide the trainees a full system of the modern processes of development of the Global Information Society, so that they emerge with an understanding of the information, socio-economic, and psychological problems, as well as ways to solve them through the use of modern means of information and advanced information technologies. The discipline focuses on the formation of the Masters and system competence in the field of information society development, as well as the modern scientific worldview.

\section{Future Direction of Social Informatics}

Strictly speaking, the problem of research in the field of Social Informatics is not limited to problems of information and the development of Information Society. Many socially important manifestations of the phenomenon of information do not necessarily relate to the information, and social science should study these and also those of the information reality.

Therefore, among the most topical and promising directions of further development of Social Informatics include the following:

1. Integrated development issues of electronic information resources and their effective use in different spheres of society.

2. System of a study on the Global Information Society based on knowledge and related issues of science, economics, education, and culture.

3. Exploring new opportunities for human development in the Information Society, including intel lectual, creative, and moral qualities.

4. Investigation of new threats and challenges in the human issues of information security and human society, including new and poorly studied phenomenon of the digital divide, information crime, computer illness, manipulation of consciousness, virtualization of the society, as well as various types of conflict in the field of information and information war.

\section{Conclusion}

The complex study of Social Informatics, not only in academic science, but in the modern education system is now an extremely relevant and socially important problem whose solution requires joint efforts of the international research and education community and, of course, the proper modernization of education and training of scientific and pedagogical personnel.

\section{References}

Kolin K.K. (1994). Social Informatics - Scientific Basis of Postindustrial Society. Social Informatics, 94, 4-23.

Kolin K.K (1995a). Social Informatics New Direction of Research on the Complex Problem of Informatics. Systems and Tools of Informatics, 7, 20-37.

Kolin K.K. (1995b). Science for the Future: Social Informatics. Information Resources of Russia, 3, 8-15.

Kolin K.K. (2000). Fundamentals of Informatics: Social Informatics: A Manual for Schools. Moscow: Academic Project.

Kolin K.K. (2001). Social Informatics. Basic Modular Program Curriculum for Higher Education. Moscow: IPI RAS.

Kolin K.K. (2003a). Social Informatics: A Manual for Schools. Moscow. Academic Project.

Kolin K.K. (2003b). Virtualization of Society - A New Threat to Its Stability. Synergetic Paradigm. Man and Society in Conditions of Instability. (pp. 449-462). Moscow. The Progress-Tradition.

Kolin K.K. (2004). Globalization and Culture. Bulletin of the Library Assembly of Eurasia, 1. 12-15. 
Kolin K.K. (2006). Information Security as a Humanitarian Problem. Open Education, 1, 86-93.

Ursul A.D. (1990). Informatization of Society: Introduction to Social Informatics. Moscow. Academy of Social Sciences

Ursul A.D. (1993). Path to the Noosphere. The Concept of Survival and Sustainable Development of Civilization. Moscow. Beam.

\section{About the Author}

Konstantin Kolin

Principal Researcher of the Institute of Informatics Problems of the Russian Academy of Sciences, Doctor of Technical Sciences, Professor, Honored Worker of Science of the Russian Federation.

E-mail:kolinkk@mail.ru 